\title{
Articulatory Variability in Cluttering
}

\author{
Mariam Hartinger ${ }^{\mathrm{a}}$ Christine Mooshammer ${ }^{\mathrm{b}, 1}$ \\ a Zentrum für Allgemeine Sprachwissenschaft (ZAS), Berlin, and \\ ${ }^{b}$ Institut für Phonetik und digitale Sprachverarbeitung, Christian-Albrechts-Universität Kiel, Kiel, Germany
}

\section{Key Words}

Cluttering - Spatial and temporal variability in speech • Fluency disorders $\cdot$ Speech motor control

\begin{abstract}
In order to investigate the articulatory processes of the hasty and mumbled speech in cluttering, the kinematic variability was analysed by means of electromagnetic midsagittal articulography. In contrast to persons with stuttering, those with cluttering improve their intelligibility by concentrating on their speech task. Variability has always been an important criterion in comparable studies of stuttering and is discussed in terms of the stability of the speech motor system. The aim of the current study was to analyse the spatial and temporal variability in the speech of three persons with cluttering (PWC) and three control speakers. All participants were native speakers of German. The speech material consisted of repetitive CV syllables and loan words such as 'emotionalisieren', because PWC have the severest problems with long words with a complex syllable structure. The results showed a significantly higher coefficient of variation for PWC in loan word production, both in the temporal and in the spatial domain, whereas the means of displacements and durations did not differ between groups. These findings were discussed in terms of the effects of the linguistic complexity, since for the syllable repetition task, no significant differences between PWC and controls were found.
\end{abstract}

Copyright $\odot 2008$ S. Karger AG, Basel

The author has changed affiliation during the course of this work. Christine Mooshammer is now at Haskins Labs, New Haven, USA.

\section{KARGER}

Fax +41613061234

E-Mail karger@karger.ch

www.karger.com (c) 2008 S. Karger AG, Basel

$1021-7762 / 08 / 0602-0064 \$ 24.50 / 0$

Accessible online at:

www.karger.com/fpl

\section{Introduction}

Cluttering is characterized by its inconstant nature: the most common symptoms are a fast and irregular speech rate, phonological speech errors such as syllable omissions, and substitutions, and mumbled speech. The severity of the symptoms depends on different factors, such as communication context, concentration, and tiredness of the speaker. Scherer [1] distinguished between individual and situational variability. Besides this intraspeaker variability, the symptoms can also differ from one speaker to another. Even though very little is known about the causes of this fluency disorder, cluttering has been characterized in the literature by as many as 65 symptoms [2]. From our point of view, the aforementioned individual and situational variability is reflected in a high articulatory variability as well.

Since variability is a suitable indicator of the stability of speech motor control in the speech production of persons with stuttering it '... has always been a hot topic in research ...' [3; p. 329]. Also in other speech motor disorders like childhood apraxia of speech [4] and dysarthria $[5,6]$, variability in word production and articulatory movements seems to be a characteristic feature.

From a speech motor control perspective, there are several explanations of these results. As was pointed out by Caruso et al. [7], higher articulatory variability in stuttering reflected an inherently unstable situation that is based on an impairment in movement sequencing. Contrary to this interpretation, van Lieshout et al. [3] discussed that variability could mark a highly efficient speech production system that is able to adapt to different

Mariam Hartinger

Centre for General Linguistics, Typology and Universals Research (ZAS)

Schützenstr. 18

DE-10117 Berlin (Germany)

Tel. +49 30201924 01, Fax +49 30201924 02, E-Mail hartinger@zas.gwz-berlin.de 
situations. However, Sick [8] verified qualitative differences between an adult person with cluttering and a fastspeaking person. She interpreted the higher scores of iterations and phonetic errors as indications for temporal disruptions in the sequencing of speech motor programs. According to these findings, Ward [9] assumed that normal speakers produce fluent speech within a limited range of variability, whereas persons with stuttering try to implement a range of articulatory strategies which results in an increasing variability.

However, knowledge regarding a normal variability of speech motor abilities is limited, and the boundary between normal and so-called pathological motor behaviour is arbitrary [3].

Speech production inherently has a certain amount of natural variability, a property which it shares with all other human motor behaviour. It is related to time-varying changes such as speech rate, stress or articulatory precision [10]. Hence, a specific motor task cannot be replicated in an absolutely identical way. This kind of tokento-token variability has been attributed (in part) to neural noise corrupting the control signals [11, 12]. Regarding the level at which variability is most prevalent, O'Dwyer and Neilson [13] found that patterns of muscle activity were reproducible across 20 repetitions both in athetoid and normal speakers, although the spatial and temporal parameters of the athetoid speakers varied significantly.

These results support the theory of an underlying invariance in the motor control system despite the fact that actual speech production is variable [10]. However, as the authors [10] state, there are more studies that show variability in repeated-trial tasks than invariance.

Up to now, only very few studies have investigated speech motor abilities of persons with cluttering and these have shown contradictory results. Seeman and Novák [14] for example, who counted the produced syllables in a 1-minute interval, found very good speech motor skills for PWC, whereas Lees et al. [15] observed limited tongue movements (see also Daly and Burnett [16]). The authors analysed videotaped recordings of reading and spontaneous speech, and they used the time-bycount measurements according to Fletcher [17]. The authors made it clear that speech motor skills should be taken into account for the diagnosis of cluttering.

There have been relatively few qualitative and quantitative studies of cluttering. In the second half of the last century, brain activities of PWC were investigated by electroencephalography. The results pointed out abnormal brain activities in $90 \%$ of the analysed PWC $[18,19]$. Interestingly, for stuttering, no $[18,19]$ or less frequent pathological brain activities $[20,21]$ were found (in 13.5 and $15.5 \%$ of the analysed persons with stuttering). Furthermore, some acoustic analyses were carried out, showing that dysfluencies occur more frequently in cluttering in comparison to stuttering $[22,23]$, and the longer a word, the more frequently dysfluencies were observed [22]. While persons with stuttering show dysfluencies more often at the beginning of words, PWC tend to make errors in the middle or at the end of words [23]. Most of the speech errors for the PWC were caused by substitutions [24].

Cluttering by way of example shows clearly that the boarders between 'normal' and 'pathological' are not fixed. For instance, the speech rate of PWC is described as extraordinarily fast and hasty. Normal speakers, however, are also capable of speaking very quickly, but their speech is usually still intelligible and not classified as pathological. Fast speakers do not exhibit as many speech errors as PWC [8]. In the literature, there are hardly any indications of how many speech errors like elisions or substitutions are 'normal' and how many are typical for cluttering. For normal speakers, Levelt [25] assumes 1 error per 1,000 words.

In this current study, our aim is to investigate the spatial and temporal kinematic variability of the fluency disorder cluttering by means of electromagnetic midsagittal articulography (EMMA). Based on the assumption that the quality of speech production in cluttering is strongly variable within speakers, and taking into account the results from the experimental studies on stuttering and other speech motor disorders discussed above, we propose the following hypothesis: PWC exhibit a higher articulatory variability when compared to controls. Motoric imprecision will be assessed by measuring the temporal and spatial token-to-token variability of articulatory gestures. Since speech rate affects the size of movement amplitudes [26], and due to the assumed fast speech rate of PWC, we expect small and short articulatory movements. All these aspects will be addressed by a kinematic study of a group of adult persons with cluttering and control speakers.

\section{Methods}

\section{Participants}

Six adult German native speakers took part in this experiment. The group of PWC consisted of 2 males and 1 female. They were diagnosed by speech pathologists on the basis of assessments of spontaneous speech and had no other speech disorders. The participants had recently taken part in one or more speech therapy 
treatments. For comparison, an age- and gender-matched control group was included. The participants were between 21 and 36 years old. In what follows, the speakers will be identified with initials that refer to the group $(\mathrm{C}=\mathrm{PWC}, \mathrm{N}=$ normal speaker, control $)$ and gender $(\mathrm{M}=$ male, $\mathrm{F}=$ female $)$ they belong to.

The dysfluencies of the PWC were mainly characterized by a fast speech rate, mumbled articulation and syllable omissions. Speaker CM1 showed prolongations instead of reductions and vice versa. Omissions appeared mostly at the end of utterances. CM2 could control his fast speech rate quite well. In his family, the same symptoms were prevalent. In comparison to the male speakers, CF3 was not aware of her fast speech. The following deteriorating factors were described by the participants in an anamnesis interview: tiredness (CM2), emotional situations such as arguments (CM1), and speaking to strangers (CM2). They could improve their speech on their own account by concentration (CM1, CM2), reading aloud (CM1), and in speaking foreign languages (CF3).

\section{Material}

The participants were instructed to produce two different tasks: repetitive $\mathrm{CV}$ sequences and test words within carrier phrases. The first task was to repeat simple CV sequences (where $\mathrm{C}=/ \mathrm{p} /, / \mathrm{t} /$, or $/ \mathrm{k} /$ and $\mathrm{V}=/ \mathrm{a} /$ ) as fast and intelligibly as possible within a 10 -second interval. The whole multiple repetition task was recorded twice.

Since the recording of spontaneous speech is not feasible in EMMA experiments, for the second task, multisyllabic words were embedded in the frame sentence 'Sage bitte' ('say

please') in order to elicit more natural utterances. The words consisted of a minimum of 5 and a maximum of 8 syllables. Loan words were chosen because PWC have particular problems with longer words with complex syllable structures [27]. Loan words were understood as words of foreign origin that were part of the German lexicon. All words contained the sequence /nali/ in which the final vowel /I/ or /i/ was either stressed and lax as in /dimenziona'listIj/ or unstressed and tense as in /dimenzionali'zi rron/ (bold letters indicate lexically stressed vowels). The vowel /a/ was realized as prestressed 1 (p1) or prestressed 2 (p2). Each of the 5 word pairs contained /a/ in the p1 and the p2 position. Each sentence was repeated 10 times in randomized order. Overall each speaker produced 100 sentences $(50 \times$ [na'li] p1, 50 $\times$ [nali] p2). Since one sensor came off during the recording session of speaker NM1, only 35 repetitions of each /nali/ were used for further analysis.

The participants were asked to speak as fast as possible, while maintaining intelligibility. If they slowed down their speech rate during the recording, they were reminded to follow the instruction.

\section{EMMA Recording}

For the present study, kinematic data were recorded by means of the Articulograph AG100 [28].

Four sensors were glued to the tongue spaced equally from 1 to $5 \mathrm{~cm}$ behind the tongue tip, one to the lower incisors for monitoring jaw movements and one to the lower lip. Two sensors on the nasion and the upper incisors served as reference coils to compensate for helmet movements during the recording session. The sampling rate for the articulatory data was $400 \mathrm{~Hz}$ and was later downsampled to $200 \mathrm{~Hz}$.
In a first step of post-processing, the data were rotated and translated so that the origin is formed by the reference coil located on the upper incisors, and the line joining the reference sensors on the upper incisors and the nasion is vertical [29]. This transformation, carried out on a sample-by-sample basis, corrects for movements of the head relative to the helmet.

The second step consisted of the rotation of the data to the participant's bite plane and a translation to the coordinates of the lower edge of the upper incisors. The occlusional plane was determined by using a custom-made $\mathrm{T}$ bar (for a more detailed description, see Hoole [29]).

The signals of the sensors were smoothed by an FIR low-pass filter with a cut-off frequency of $30 \mathrm{~Hz}$.

\section{Data Segmentation}

Figure 1 represents an EMMA display with tongue tip movements during the production of /nali/. The acoustic signal is shown in the upper panel; in the middle panel, the vertical movement of the tongue tip is represented, and the lower panel shows the tangential velocity signal. During the articulation of the sequence /nali/, four gestures were produced. The vertical lines in the figure indicate the first tongue tip closing gesture towards $/ \mathrm{n} /$. The following gestures are the opening gesture (OG) towards the vowel $/ a /$, the closing gesture towards $/ 1 /$, and the OG towards $/ \mathrm{i} /$.

Using the tongue tip tangential velocity signal (in $\mathrm{cm} / \mathrm{s}$ ), shown in the lower panel in figure 1 , the onsets and offsets of each gesture were determined semi-automatically by the $20 \%$ threshold values of the left and right minimum [29], surrounding the velocity peak (see Tasko and Westbury [30] for a methodical discussion of parsing movements into movement units).

For durational measurements, the time between the movement onsets and offsets (again determined by a 20\% threshold value) was calculated for each gesture. For computing displacements, the tangential velocity signal was integrated between the two minima. In comparison to the normal euclidean distance, i.e. the length of the straight line connecting two coordinates, this method measures the real, often curved length of the path the tongue travels [31].

Since the second gesture, i.e. the tongue tip OG from the nasal $/ \mathrm{n} /$ towards the vowel /a/ in /nali/, showed the most interesting articulatory phenomena, we focussed exclusively on this OG in this study.

For the syllable repetition task, one closing gesture towards the stops $/ \mathrm{p} / \mathrm{l} / \mathrm{t} /$, or $/ \mathrm{k} /$ and one OG towards $/ \mathrm{a} /$ were measured for each syllable. For bilabial stops, lower lip signals were measured; for alveolar stops, the tongue tip sensor and for velar stops, the tongue back sensor were used.

\section{Exclusion Criteria}

The exclusion criteria in this study differ from comparable studies on stuttering $[7,32-34]$ in that they usually only analysed fluent utterances as judged by speech and language pathologists. We only excluded data when analysis showed incomplete articulatory movements (see below).

Because the participants were instructed to repeat sentences that contained speech errors, there were sometimes several versions of one sentence. In such cases, only the last improved version was analysed and included in the statistical analyses. The number of speech errors and the kind of phonological error (substitution, 
Fig. 1. EMMA display with the articulatory labelling criteria for the loan words. Upper panel = audio; middle panel = vertical movement of the tongue tip sensor; lower panel = tongue tip tangential velocity (TV) of the 4 gestures (vertical lines). The vertical bold lines demarcate onset (left minimum) and offset (right minimum) of the opening gesture from $/ \mathrm{n} /$ to /a/ (20\% threshold values). CG = Closing gesture, upward movement of the tongue tip; $\mathrm{OG}=$ opening gesture, downward movement. The hatched area was integrated in order to calculate the displacement of the opening gesture.

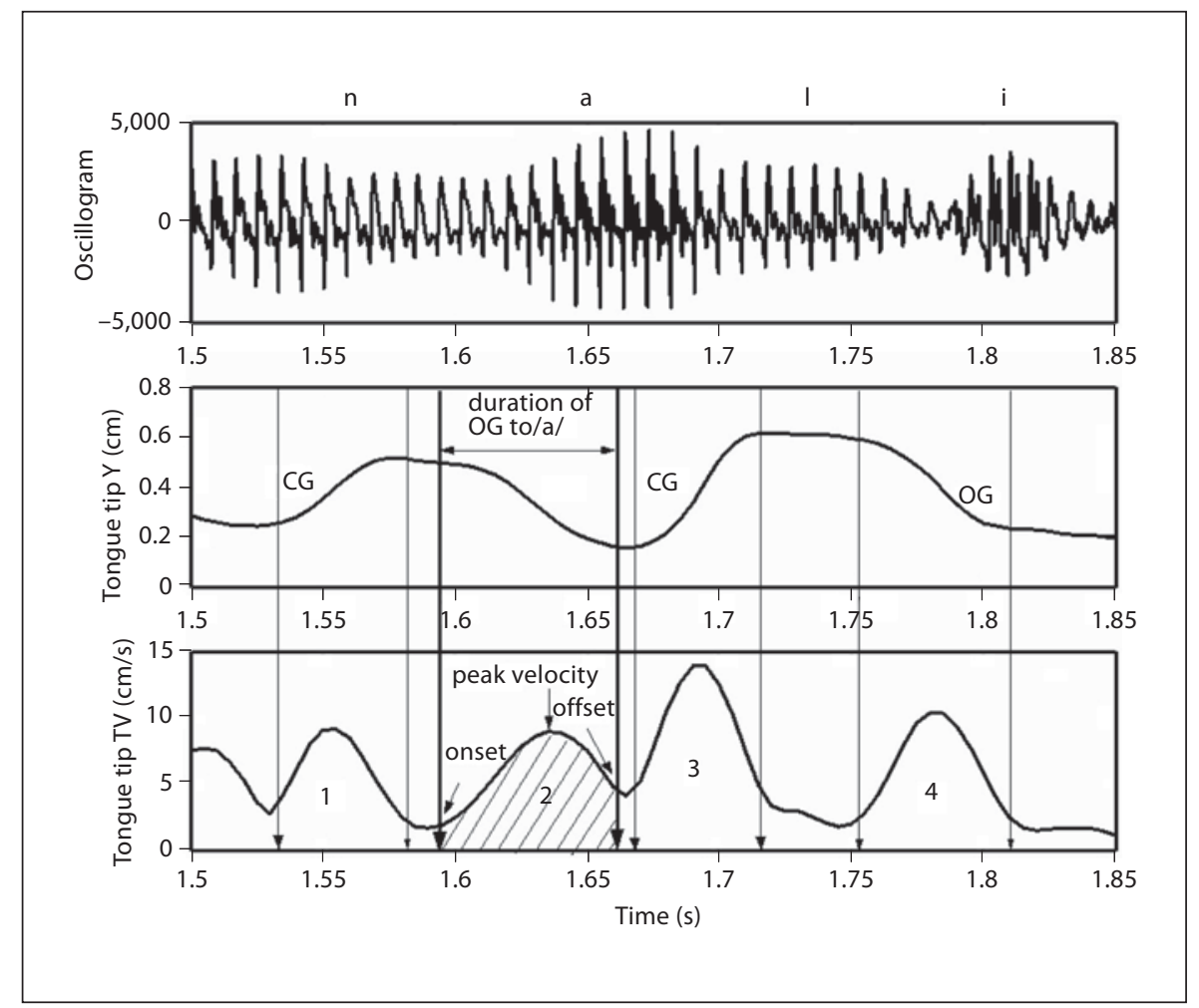

contamination) were only relevant for the descriptive statistics. Since all recordings were intelligible, it was not necessary to judge the 'fluent productions' by speech pathologists.

In the analyses of the articulatory data, items were excluded from the statistical analyses if movements could not be segmented. That means that if there was no left or right minimum or when complete gestures were reduced or elided (examples are shown in fig. 2), these data were included in the qualitative description only (see frequency values in table 1).

\section{Statistics}

Statistical analyses were performed for the dependent variables movement duration and displacement. Because one of the major aims of this study was to assess the differences in variability between groups, in addition to the mean durations and displacements we calculated the coefficient of variation. The coefficient of variation is based on the formula [(standard deviation $\times 100) /$ mean], and has the advantage over the standard deviation of being independent of the magnitude of the mean value. In order to evaluate whether PWC differ from controls with respect to their positional and temporal data, repeated-measures ANOVAs were calculated with group (PWC or control) as between-subject factor. The within-subject factor was stress ( $\mathrm{p} 1 / \mathrm{p} 2$ condition) for the loan word task. We are aware of the fact that 3 speakers per group is a very small number. Therefore, results of the statistics will only be discussed as tendencies.

Articulatory Variability in Cluttering

\section{Results}

All statistical calculations were based on the OG to /a/ within /nali/ of the 10 repetitions of each loan word. Articulatory analyses of the syllable repetitions /pa/, /ta/, $/ \mathrm{ka} /$ also focused on the OG to the /a/.

\section{Qualitative Assessment of Reduction Phenomena}

As was pointed out in the method section above, some of the produced items had to be excluded from further analyses due to gesture deletion or reduction. In this section, we describe the group-specific patterns of reduction phenomena because one of the most frequently described symptoms of cluttering are omission and the deletion of segments and syllables. Figure 2 demonstrates the reduction phenomenon, exemplified for speaker CM2's tangential velocity signal of the tongue tip during /nali/ for 9 of the 10 repetitions of the word 'emotionalisieren' in the $\mathrm{p} 2$ condition. Informal judgements of 6 out of 7 speech and language therapists rated these repetitions as 'very intelligible' to 'well intelligible'. Only 1 listener judged the last 2 repetitions as not intelligible. This indicates that even radical gestural reduction did only

Folia Phoniatr Logop 2008;60:64-72 


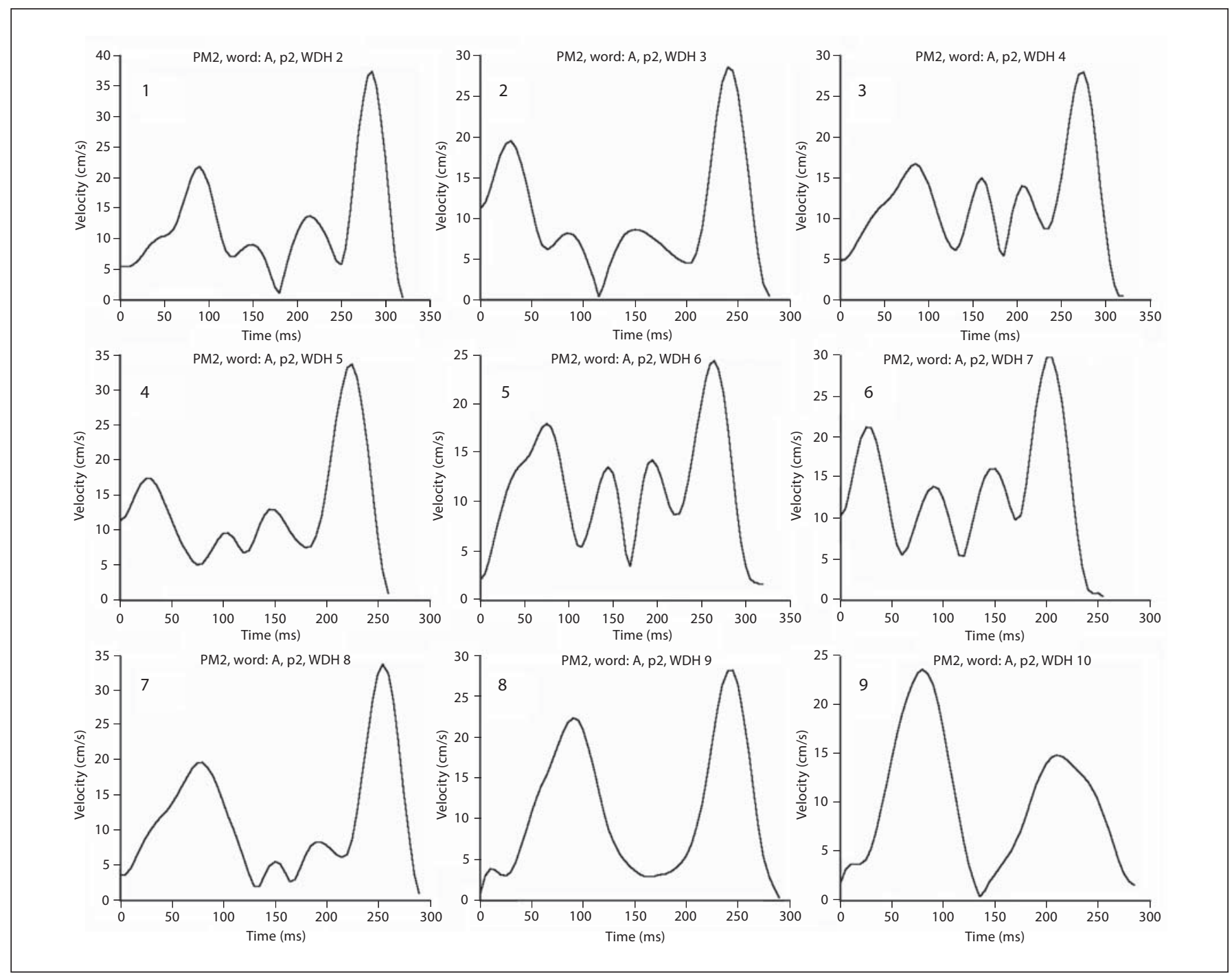

Fig. 2. Tangential velocities of the tongue tip movement of CM2 during 9 repetitions of /nali/ in 'emotionalisieren' in the $\mathrm{p} 2$ condition.

partly affect the intelligibility ratings of professional therapists.

Table 1 shows the absolute and relative frequency of data which had to be excluded from further analyses because articulatory movements of /nali/ were extremely reduced or even elided. It can be seen that exclusion was necessary much more frequently for PWC than for the control group. For speaker CM2, it was impossible to analyse nearly half of his data (42\%) in the pl condition. In comparison to the /nali/ produced by control speaker NM1 shown in figure 1, it is noticeable here that the second and third gesture always present target undershoot, i.e. the two medial velocity peaks are much smaller than the first and the fourth, whereas in figure 1 the opposite is the case. In the panels 8 and 9 of figure 2 , these gestures were completely deleted, leaving only 2 velocity peaks instead of 4 . In such cases, data were excluded from statistical calculations due to the missing values. As table 1 illustrates in the bottom part, this was true for CM2 in $24 \%$ (p1) and 6\% (p2) of the OG. In contrast, in the syllable repetition task, no imprecise articulatory movements were observed, thus all opening and closing gestures could be analysed. 


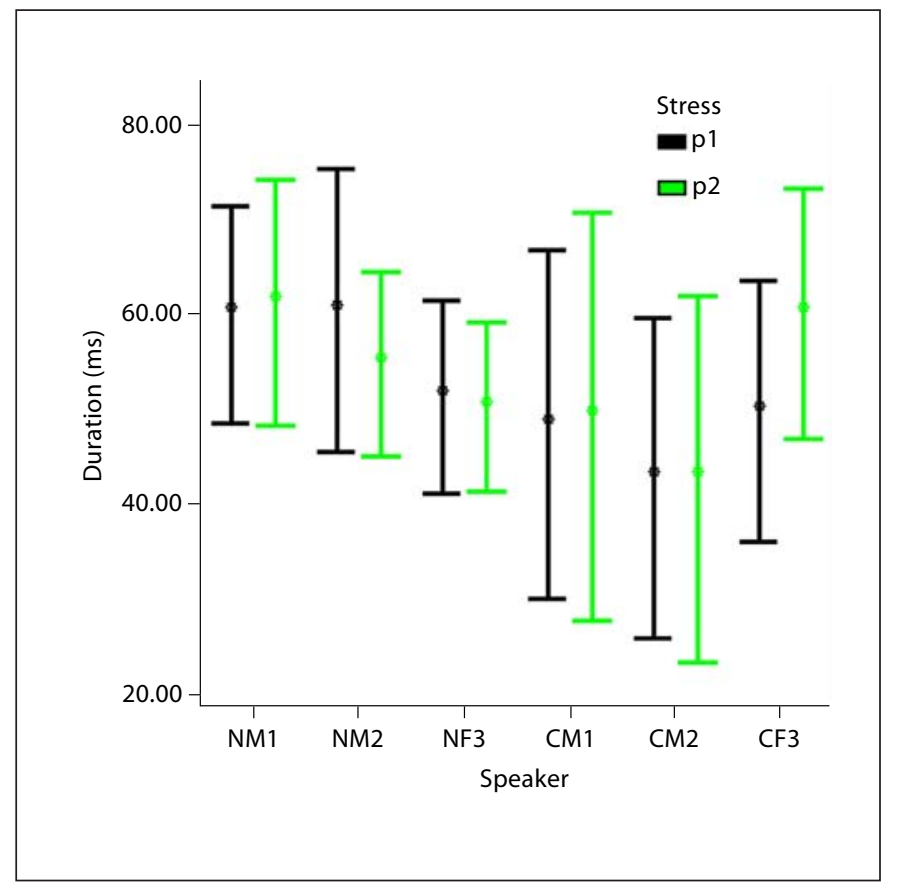

Fig. 3. Means and standard deviations (1 SD) of the durations of the $\mathrm{OG}$ of /nali/ in the $\mathrm{p} 1 / \mathrm{p} 2$ condition.

Table 1. Absolute and relative frequency of repeated sentences, data that could not be analysed, and deletion of the OG to /a/ in the $\mathrm{p} 1$ and $\mathrm{p} 2$ condition of /nali/

\begin{tabular}{|c|c|c|c|c|c|c|}
\hline \multirow{2}{*}{$\begin{array}{l}\text { Condi- } \\
\text { tion }\end{array}$} & \multicolumn{3}{|c|}{ Controls } & \multicolumn{3}{|l|}{ PWC } \\
\hline & NM1 & NM2 & NF3 & CM1 & CM2 & CF3 \\
\hline \multicolumn{7}{|c|}{ Repeated sentences } \\
\hline p1 & $3(8.6)$ & $1(2)$ & $2(4)$ & $1(2)$ & $10(20)$ & $6(12)$ \\
\hline p2 & $2(5.7)$ & & & & $6(12)$ & $10(20)$ \\
\hline \multicolumn{7}{|c|}{ Excluded data } \\
\hline $\mathrm{p} 1$ & & $1(2)$ & $1(2)$ & $7(14)$ & $21(42)$ & \\
\hline $\mathrm{p} 2$ & $2(5.7)$ & $13(26)$ & $1(2)$ & $16(32)$ & $11(22)$ & $6(12)$ \\
\hline \multicolumn{7}{|c|}{ Deletion of OG to /a/ } \\
\hline $\mathrm{p} 1$ & & & & & $12(24)$ & \\
\hline p2 & & & & & $3(6)$ & \\
\hline
\end{tabular}

Figures in parentheses are percentages.

Speaker CF3 produced omissions like [konstitsiona'listIf] instead of [konstitutsiona'listif). Furthermore, a high number of breakups were observed. Therefore, it was often necessary to ask CF3 to repeat the sentence. The frequency of repeated sentences is presented in the

Articulatory Variability in Cluttering

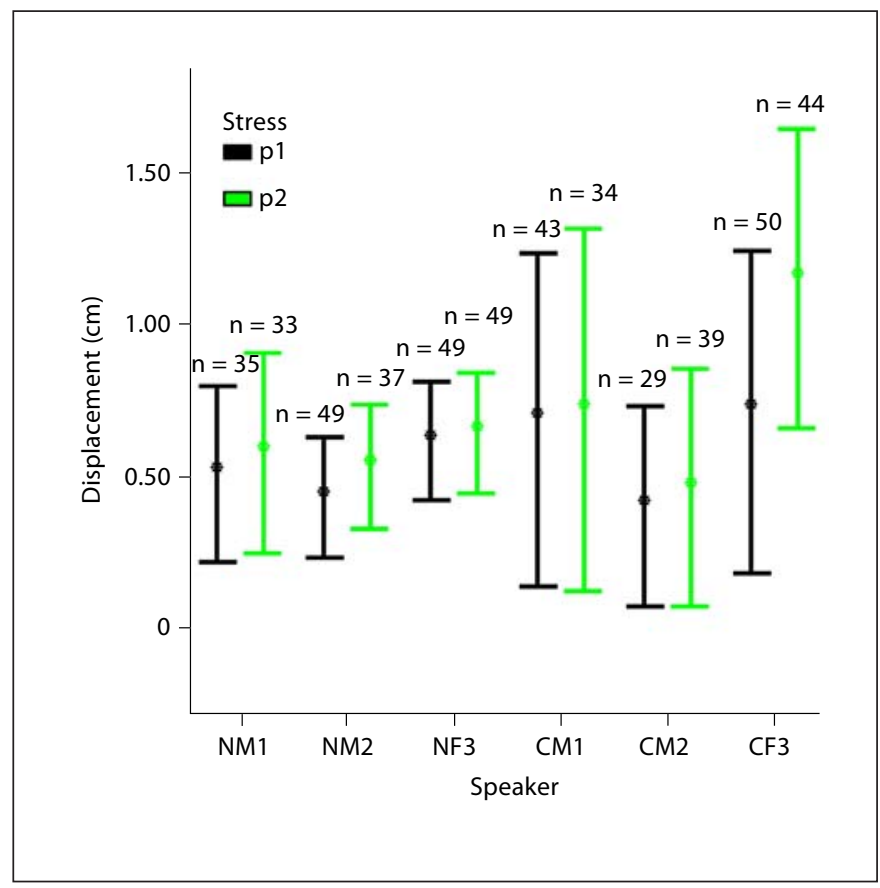

Fig. 4. Means and standard deviations (1 SD) of the displacements of the OG of /nali/ in the $\mathrm{p} 1 / \mathrm{p} 2$ condition.

Table 2. Coefficient of variation in percent for the duration and displacements of the OG of /nali/ in the $\mathrm{p} 1 / \mathrm{p} 2$ condition

\begin{tabular}{|c|c|c|c|c|c|c|}
\hline & \multicolumn{3}{|c|}{ Controls } & \multicolumn{3}{|l|}{ PWC } \\
\hline & NM1 & NM2 & NF3 & CM1 & CM2 & CF3 \\
\hline \multicolumn{7}{|c|}{ Duration } \\
\hline $\mathrm{p} 1$ & 9.5 & 12.3 & 9.9 & 19.0 & 19.7 & 13.9 \\
\hline $\mathrm{p} 2$ & 10.6 & 8.9 & 8.9 & 21.8 & 22.6 & 11.0 \\
\hline \multicolumn{7}{|c|}{ Displacement } \\
\hline $\mathrm{p} 1$ & 28.4 & 22.9 & 15.7 & 40 & 41.2 & 37.2 \\
\hline p2 & 28.6 & 19.1 & 15.4 & 41.6 & 42.1 & 21.4 \\
\hline
\end{tabular}

bottom lines of table 1. Generally, persons who cluttered tended to exhibit more sentence repetitions than controls.

\section{Articulatory Variability}

Durations and Displacements of Loan Words

Table 2 shows the coefficients of variation for the durations and displacements of the OG in /nali/ in the p1 and $\mathrm{p} 2$ condition. A higher coefficient of variation was found for the durations produced by PWC compared to

Folia Phoniatr Logop 2008;60:64-72 
Table 3. Results of the repeated-measures ANOVA for the duration and displacements of the OG of /nali/

\begin{tabular}{|c|c|c|c|c|c|}
\hline & \multirow[t]{2}{*}{ d.f. } & \multicolumn{2}{|l|}{ Means } & \multicolumn{2}{|c|}{ Coefficients of variation } \\
\hline & & F value & $\mathrm{p}$ & F value & $\mathrm{p}$ \\
\hline Duration of OG & 4 & & & & \\
\hline Group & 1 & 2.675 & 0.177 (n.s.) & 8.101 & $0.047^{*}$ \\
\hline Stress & 1 & 0.226 & 0.660 (n.s.) & 0.005 & 0.946 (n.s.) \\
\hline Stress $\times$ group & 1 & 2.065 & 0.224 (n.s.) & 0.771 & 0.430 (n.s.) \\
\hline Displacement of OG & 4 & & & & \\
\hline Group & 1 & 0.801 & 0.421 (n.s.) & 8.090 & $0.047^{*}$ \\
\hline Stress & 1 & 3.397 & 0.139 (n.s.) & 0.969 & 0.381 (n.s.) \\
\hline Stress $\times$ group & 1 & 0.671 & 0.459 (n.s.) & 0.289 & 0.619 (n.s.) \\
\hline
\end{tabular}

n.s. $=$ Not significant. ${ }^{*} \mathrm{p}<0.05$.

the control group, e.g. the values of CM2 at 19.7 and $22.6 \%$ scatter over a much wider range from the mean than the values of controls with a maximum of $12.3 \%$. The coefficients of the displacements exhibited higher values in general, and the spatial data of the PWC varied by about $40 \%$. CF3 differed less from the controls than the male PWC. For example, especially the temporal (13.9 and $11 \%)$ as well as the spatial variability ( $\mathrm{p} 1=37.2 \%$ and p2 $=21.4 \%$ ) was somewhat lower than for the male PWC.

Figures 3 and 4 present the standard deviations and means of the durations and displacements of the OG for the two stress conditions. Contrary to our expectations, the mean durations did not differ significantly between the group of PWC and controls. In the displacements, speaker CM2 who produced only 29 instead of 50 analysable repetitions showed a smaller standard deviation than the other PWC. However, as shown by the upper edges of the whiskers for the standard deviations, CM1 and CF3 produced much larger amplitudes than the controls.

Table 3 contains the results of the repeated-measures ANOVA both for the means and the coefficients of variation of the spatial and temporal data of /nali/. The ANOVA (within-subject factors $=\mathrm{p} 1 / \mathrm{p} 2$ condition, between-subject factor $=$ controls vs. PWC) for the means regarding the duration and displacements of the OG showed no significant results between clutterers and controls. However, in terms of the coefficient of variation significant differences were found between the group of PWC and the group of controls. As can be seen in table 3, the calculated ANOVA for the comparison of stress ( $\mathrm{p} 1$ vs. $\mathrm{p} 2$ condition) and for the interaction between stress and group (normal vs. PWC) showed no significant effects.
Durations and Displacements of Syllable Sequences

Since for the syllable repetition task there was no reasonable within-subject factor, simple $t$ tests were calculated with group as the independent variable. For the means of durations and displacements of the OG in the syllable production of $/ \mathrm{pa} /$, $/ \mathrm{ta} / \mathrm{and} / \mathrm{ka} /$, no significant results were found ( $\mathrm{t}$ values of duration/displacement: $\mathrm{p}=0.71 / 2.01 ; \mathrm{t}=0.71 / 0.59 ; \mathrm{k}=0.73 / 0.89$; all n.s.). Concerning the spatial and temporal variability (coefficient of variation) in these syllable sequences, PWC and controls did not differ significantly either $(\mathrm{p}=0.83 /-0.04$; $\mathrm{t}=1.01 /-0.5 ; \mathrm{k}=0.42 /-0.81 ;$ all n.s). Therefore, the simpler task of repeating simple CV syllables was performed in a similar manner by PWC and controls.

\section{Discussion}

The aim of this study was to investigate the articulatory variability of PWC. Remarkably high coefficients of variation were found for the spatial and temporal data of PWC. The ANOVA calculations (table 3) indicated significant differences for the coefficient of variation between PWC and controls regarding the word material but not for the syllable repetitions.

The results of the present study are consistent with the findings on stuttering that present more variable kinematic parameters such as durations, amplitudes, and velocities $[7,9,35]$. The increased variability in stuttering was interpreted as a consequence of the usage of different articulatory strategies in order to avoid dysfluencies [9].

A noticeable finding of this study is that the movement data of PWC more frequently showed gestural re- 
duction, target undershoot, and gestural deletion compared to controls (table 1; fig. 2). This change between precise and imprecise articulation, restricted to complex words, can be interpreted as a characteristic result of the study.

In comparison to controls, PWC might be more uncertain about their own speech production because they are aware of their problems and often do not know how to improve their speech quality. They control and vary their speech again and again. For 1 PWC (CF3), breakups within words were observed (see table 1 for number of repetitions). This might indicate that she always expects speech errors and therefore she stops speaking although no errors have occurred.

According to our second hypothesis, shorter and smaller articulatory movements were expected for the PWC. However, no significant results could be found for durations and displacements between the two groups - neither for the word material nor for the syllables. But we should not forget that more instances of movement data had to be excluded for the PWC because of gestural reduction and extreme target undershoot. For 2 PWC, CM1 and CF3, we also found extremely large movement displacements, as indicated by the upper edges of the standard deviations in figure 4 . Thus, variability remains the most important result of the study. Additionally, with regard to the qualitative analysis of the movement patterns, highly variable data were found.

This fits quite well the general pattern found for PWC, namely that their speech production generally showed a higher variability due to speech errors, breakups within words, incomplete articulation, and an irregular speech rate (table 1).

Zimmermann [35] explained the instability in stuttering with an imbalance in the afferent-efferent nerve impulses and the critical spatial-temporal relationship in the command execution. This is one reason why research and treatment of cluttering should focus more strongly on the processes in the central nervous system. Not only for producing intelligible speech but also for the execution of other gross and fine movements is it necessary that the motor system with the motor cortex, the basal ganglia, and the cerebellum works without any disruptions. Before reaching the muscles, the commands pass through the cerebellum, where the movements are modulated $[36,37]$. The basal ganglia determine parameters like displacement, direction, velocity and strength of the movements. In order to understand the processes in the brain, it would be a worthwhile investigation to use functional magnetic resonance imaging for PWC. A very re- cent study with right-handed persons with stuttering has shown a right-hemispheric hyperactivity [38]. After speech therapy, a more widespread activation in the speech and language areas on the left hemisphere could be observed.

An additional explanation for the observed variability patterns is the effect of speech rate. According to Fitts' [39] law, an increase in speech rate causes an increase in movement variability. Ward [9], who analysed utterances of persons with stuttering in a normal, fast, and slow speech rate, confirmed this relationship. Furthermore, in the present study, PWC showed a high temporal variability, which makes it difficult to discern the effect of speech rate and intrinsic variability.

Since for the syllable repetitions no higher variability could be observed, it is assumed that the speech production system of the PWC seemed to work in a more stable way during the syllable repetition task than during the articulation of loan words. Stop-vowel sequences are the most frequent syllable structures in general and are also the first linguistic units to be acquired during the speech development of human beings (for a recent overview, see Ackermann et al. [40]). This could explain why PWC accomplished the syllable repetition task with ease.

Another relevant aspect is the effect of linguistic complexity on speech production and this is well documented in van Lieshout et al. [3]. By using the Index of Phonetic Complexity, Weiss and Jakielski [41] gave evidence for an increase in dysfluencies in stuttering children due to the phonetic complexity. Findings by Smith and Kleinow [42] showed greater movement variability for all speakers, not only for stuttering, in syntactically more complex utterances. In terms of the present results, it might be possible that the production of the complex loan words was more difficult for the PWC than for controls. In a previous study, van Lieshout [33] explained the complexity of long words from a speech production view. According to him, the brain has to prepare more production units for long words than for short words. While formulating, storing, or executing these commands, there are several sources of errors. It should also be considered that complex words exhibit less common articulatory and prosodic patterns [33]. This seems to be the case for the described test corpus in our study. Since an increase in dysfluency in cluttering was proved for longer words in an acoustic study [22], further investigations should follow up this question, for instance by using the Index of Phonetic Complexity, and by means of functional magnetic resonance imaging. 
As a higher spatial, temporal as well as qualitative variability was the most important outcome of the study, the effects of the linguistic complexity on speech production should be taken into account in future research work, as well as aspects of brain activity during the speech pro- duction process. According to the conclusion of van Riper [43], it is possible that not only stuttering but also cluttering is caused by tiny lags and disruptions in the timing of the speech production process.

\section{References}

1 Scherer A: Poltern und Stottern als Ausdruck der emotionalen Befindlichkeit: ein Erfahrungsbericht aus sprachtherapeutischer Sicht. Sprache Stimme Gehör 2003;27 88-91.

$\checkmark 2$ St Louis KO, Hinzman AR: Studies of cluttering: perceptions of cluttering by speechlanguage pathologists and educators. J Fluency Disord 1986;11:131-149.

3 van Lieshout PHHM, Hulstijn W, Peters HFM: Searching for the weak link in the speech production chain of people who stutter: a motor skill approach; in Maassen B, Kent R, Peters H, van Lieshout PHHM, Hulstijn W (eds): Speech Motor Control in Normal and Disordered Speech. Oxford, Oxford University Press, 2004, pp 313-355.

$\checkmark 4$ Marquardt TP, Jacks A, Davis BL: Token-totoken variability in developmental apraxia of speech: three longitudinal case studies. Clin Linguist Phon 2004;18:127-144.

5 McHenry MA: The effect of pacing strategies on the variability of speech movement sequences in dysarthria. J Speech Lang Hear Res 2003;46:702-710.

6 Metter JE, Hanson WR: Clinical and acoustic variability in hypokinetic dysarthria. J Commun Disord 1986;19:347-366.

7 Caruso AJ, Abbs JH, Gracco VL: Kinematic analysis of multiple movement coordination during speech in stutterers. Brain 1988;111: 439-455.

8 Sick U: Spontansprache bei Poltern. Forum Logopädie 2000;4:7-16.

$\checkmark 9$ Ward D: Intrinsic and extrinsic timing in stutterers' speech: data and implications. Lang Speech 1997;40:289-310.

10 Alfonso P, van Lieshout P: A dynamical account of the organization and coordination of speech gestures; in Starkweather CW, Peters HFM (eds): Proceedings First World Congress on Fluency Disorders. Munich, International Fluency Association, 1995, vol 1, pp 6-10.

-11 Perkell JS, Nelson L: Variability in production of the vowels /i/ and /a/. J Acoust Soc Am 1985;77:1889-1895.

12 Mooshammer C, Perrier P, Fuchs S, Geng C, Pape D: An EMMA and EPG study on tokento-token variability. Arbeitsber Inst Phonet Digitale Sprachverarbeitung Kiel 2004;36: 47-63.
13 O’Dwyer NJ, Neilson PD: Voluntary muscle control in normal and athetoid dysarthric speakers. Brain 1988;111:877-899.

14 Seeman M, Novák A: Über die Motorik bei Polterern. Folia Phoniatr 1963;15:170-176.

15 Lees RM, Boyle BE, Woolfson L: Is cluttering a motor disorder? J Fluency Disord 1996;21: 281-287.

16 Daly DA, Burnett ML: Cluttering: assessment, treatment planning, and case study illustration. J Fluency Disord 1996;21:239248.

17 Fletcher SG: Time-by-count measurement of diadochokinetic syllable rate. J Speech Hear Res 1972;15:763-770.

18 Luchsinger R, Landolt H: Elektroencephalographische Untersuchungen bei Stotterern mit und ohne Polterkomponente. Folia Phoniatr 1951;3:135-150.

19 Luchsinger R, Landolt H: Über das Poltern, das sogenannte 'Stottern mit Polterkomponente' und deren Beziehung zu den Aphasien. Folia Phoniatr 1955;7:12-43.

20 Morávek M, Langová J: Some electrophysiological findings among stutterers and clutterers. Folia Phoniatr 1962;14:305-316.

21 Langová J, Morávek M: An Experimental Study of Stuttering and Cluttering. Praha, Academia, 1966.

22 Rieber RW: A study in psycholinguistics and communication disorders. Linguistics 1975; 160:33-70.

23 Rieber RW, Smith N, Harris B: Neurological aspects of stuttering and cluttering; in Rieber RW (eds): The Neuropsychology of Language. New York, Plenum Press, 1976, pp 45-66.

24 St Louis KO, Hinzman AR, Hull FM: Studies of cluttering: disfluency and language measures in young possible clutterers and stutterers. J Fluency Disord 1985;10:151-172.

25 Levelt WJM: Speaking, ed 2. Cambridge, MIT Press, 1991.

26 Ostry DJ, Munhall KG: Control of rate and duration of speech movements. J Acoust Soc Am 1985;22:640-648.

27 Luchsinger R, Arnold GE: Lehrbuch der Stimm- und Sprachheilkunde, ed 2. Wien, Springer, 1959.

28 Carstens: Articulograph AG100. Elektromagnetisches Artikulations-Meßsystem. Benutzerhandbuch. Göttingen Carstens Medizinelektronik GmbH, 1992.
29 Hoole P: Issues in the acquisition, processing, reduction and parameterization of articulographic data. Forschungsber Inst Phonet Sprachl Kommun München 1996;34: 158-173.

30 Tasko SM, Westbury JR: Defining and measuring speech movement events. J Speech Lang Hear Res 2002;45:127-142.

-31 Mooshammer C, Hoole P, Kühnert B: On loops. J Phonet 1995;23:3-21.

32 Zimmermann G: Articulatory dynamics of fluent utterances of stutterers and nonstutterers. J Speech Hear Res 1980;23:95-107.

33 van Lieshout PHHM: Motor planning and articulation in fluent speech of stutterers and nonstutterers; thesis, Nijmegen Institute for Cognition and Information, Nijmegen, 1995.

-34 McClean MD, Tasko SM, Runyan CM: Orofacial movements associated with fluent speech in persons who stutter. J Speech Lang Hear Res 2004;47:294-303.

35 Zimmermann G: Stuttering: a disorder of movement. J Speech Hear Res 1980;23:122136.

36 Loosch E: Allgemeine Bewegungslehre. Wiebelsheim, Limpert, 1999.

37 Hülshoff T: Das Gehirn. Bern, Huber, 1996.

38 Neumann K, Preibisch C, Euler HA, von Gudenberg AW, Lanfermann H, Gall V, Giraud AL: Cortical plasticity associated with stuttering therapy. J Fluency Disord 2005; 30:23-39.

39 Fitts PM: The information capacity of the human motor system in controlling the amplitude of movement. J Exp Psychol 1954;47: 381-391.

40 Ackermann H, Hertrich I, Mathiak K: Neurobiologische Grundlagen der Sprachlautwahrnehmung: Klinische und funktionellbildgebende Befunde. Sprache Stimme Gehör 2005;29:112-120.

41 Weiss AL, Jakielski KL: Phonetic complexity measurement and prediction of children's disfluencies: a preliminary study. 4 th Nijmegen Conf Speech Motor Control Stuttering, Nijmegen, 2001, pp 278-281.

42 Smith A, Kleinow J: Kinematic correlates of speaking rate changes in stuttering and normally fluent adults. J Speech Lang Hear Res 2000;43:521-536.

43 van Riper C: Final thoughts about stuttering. J Fluency Disord 1990;15:317-318. 